\title{
Therapeutic Improvement of Scarring: Mechanisms of Scarless and Scar-Forming Healing and Approaches to the Discovery of New Treatments
}

\author{
Nick L. Occleston, Anthony D. Metcalfe, Adam Boanas, Nicholas J. Burgoyne, Kerry Nield, \\ Sharon O'Kane, and Mark W. J. Ferguson
}

Renovo Group plc, Core Technology Facility, 48 Grafton Street, Manchester M13 9XX, UK

Correspondence should be addressed to Anthony D. Metcalfe, anthony.metcalfe@renovo.com

Received 15 March 2010; Accepted 17 June 2010

Academic Editor: Hayes B. Gladstone

Copyright ( $) 2010$ Nick L. Occleston et al. This is an open access article distributed under the Creative Commons Attribution License, which permits unrestricted use, distribution, and reproduction in any medium, provided the original work is properly cited.

\begin{abstract}
Scarring in the skin after trauma, surgery, burn or sports injury is a major medical problem, often resulting in loss of function, restriction of tissue movement and adverse psychological effects. Whilst various studies have utilised a range of model systems that have increased our understanding of the pathways and processes underlying scar formation, they have typically not translated to the development of effective therapeutic approaches for scar management. Existing treatments are unreliable and unpredictable and there are no prescription drugs for the prevention or treatment of dermal scarring. As a consequence, scar improvement still remains an area of clear medical need. Here we describe the basic science of scar-free and scar-forming healing, the utility of preclinical model systems, their translation to humans, and our pioneering approach to the discovery and development of therapeutic approaches for the prophylactic improvement of scarring in man
\end{abstract}

\section{Introduction}

Anything greater than a superficial injury to the skin of children and adults results in scar formation. Scarring is a major cause of physical and psychological morbidity [1-8]. Whilst various studies have utilised a range of model systems that have increased our understanding of the pathways and processes underlying scar formation, they have not been typically translated to the development of effective therapeutic approaches for scar management. This is evidenced by the fact that despite a number of potential treatment regimens, no single therapy is accepted universally as the standard of care [9-11]. As such, scar improvement still remains an area of clear medical need. Herein, we describe the basic science underlying scar-free and scar-forming healing, the utility and translation of preclinical model systems to humans, and our pioneering approach to the discovery and development of therapeutic approaches for the prophylactic improvement of scarring in man.

\section{Scar-Free and Scar-Forming Healing}

Scarring and wound healing occur within a spectrum ranging from the ability to completely regenerate tissue in amphibians, through scar-free healing in embryos of different mammalian species, to scar-forming healing in children and adults. From an evolutionary perspective, the scarring response results in rapid replacement of missing tissue and, although suboptimal in terms of appearance and function, results in a reduction in the likelihood of infection and an increased likelihood of organism survival following injury. The ability of organisms to heal wounds without scar formation has nevertheless been demonstrated in the early embryos of a range of mammalian species including mice, rats, rabbits, sheep, pigs, marsupials, and monkeys [12]. Comparison of the architecture of regenerated skin in embryos with that of adults demonstrates that it is the organisation of collagen that is largely responsible for scar formation. Whereas the dermis of embryonic skin is restored 
to the normal "basket weave" architecture of collagen, in adult scars the collagen is abnormally organised in parallel bundles of fine fibres that are distinct from the normal skin (Figure 1). It is of particular note that there appear to be no major differences between the composition of the dermal tissue of scar-free and scar-forming healing. This indicates that scarring is primarily a failure of the regeneration of the normal skin structure rather than a biochemical problem related to an abnormal composition of the scar tissue [13].

The mechanisms underlying scar-free and scar-forming healing have been studied at the molecular, biochemical, and cellular level. Whilst there are a number of differences that have been identified between healing in the embryo and the adult, many of these are not mechanistically causative. In illustration, the mammalian embryo is surrounded by the sterile aqueous environment of the amniotic fluid, whereas adult wounds are exposed to air and a range of potentially contaminating agents including bacteria and foreign bodies. Originally, it was thought that the sterile aqueous environment provided by the amniotic fluid was important in scarfree healing. However, studies on marsupials such as the opossum, which complete development in their mother's pouch, proved otherwise [14]. In this model, incisional wounds were made in young pouch opossums and at an equivalent embryonic time to mouse embryos in an amniotic environment. Pouch opossums, like embryonic mammals, were found to heal without scarring despite developing outside of a sterile amniotic environment. Following injury to the embryo, the inflammatory response (by virtue of a less than mature immune system) is less marked and differs in terms of the types and number of inflammatory cells that enter the wound [15]. Finally, whilst the profiles and quantities of growth factors and cytokines associated with scar-free healing are often different to those in adult scarforming healing [16-19], there are only a few of these factors that present themselves as potential therapeutic targets $[12$, $13,20]$.

Data from our studies and those in the literature demonstrate that the scarring response represents a continuous spectrum of phenotypes in organisms ranging from scarfree through to scar-forming healing (Figure 2). Both scarfree and scar-forming healing can occur in the same animal, for example, an axolotl can regenerate an amputated limb but heals an incisional wound on the flank with a scar; if part of the liver is removed in mammals by hepatectomy, the liver regenerates, whilst stab wounds made to the liver heal with scarring; MRL and other strains of adult mice including athymic nude- $n u$ mice regenerate ear wounds, where the absence of T-lymphocytes in wounded ears provides a microenvironment conducive to regeneration of mesenchymal tissues, which is in contrast to wounds made on the dorsum of MRL mice that heal with a scar; penetrating wounds to the cheek of humans heal with scarring of the external cutaneous surface but the oral mucosal surface heals with no discernable scar $[13,21-26]$. The likelihood is that tissue repair and regeneration are not that dissimilar and, in fact, share many common mechanisms that differ very subtly. Furthermore, the fact that all mammalian embryos exhibit a regenerative capacity demonstrates that even adult mammals contain the genetic program for regeneration. The above observations are critically important as they demonstrate that organisms retain the ability to heal via a regenerative as well as a scar-forming process, which gives a biological basis for therapeutic modulation of the healing response in adults to reduce scar formation.

\section{In Vitro and In Vivo Models to Investigate the Mechanisms of Scarring and Evaluate Potential Treatments}

A number of in vitro and in vivo models have been used to investigate the mechanisms underlying the healing and scarring response. The range of model systems, their uses and limitations are summarised below.

The healing and scarring response consists of a robust series of complex, dynamic and interacting cellular, and molecular processes including haemostasis, the inflammatory response, granulation tissue formation, and remodelling. The functions of the cell types involved in these processes are also regulated by a wide range of extracellular stimuli including growth factors/cytokines as well as interaction with the extracellular matrix [27], which elicit effects by cell surface receptors and a range of intracellular signalling cascades that result in changes in gene and protein expression. Taken together, these events contribute to complex dynamic microenvironments within the injured tissue during healing and scar maturation with which resident and infiltrating cells interact. A number of in vitro models have been utilised to investigate the various aspects of the healing and scarring response at the molecular and cellular level and include different cell types (e.g., neutrophils, macrophages, lymphocytes, keratinocytes, melanocytes, fibroblasts, and endothelial cells) and different molecular and cellular processes (e.g., signal transduction, gene expression, proliferation, migration, growth factor production, extracellular matrix production, and remodelling) [28-32]. Whilst in vitro models represent applicable systems to study individual components, these systems do not always accurately model the vastly more complex and interactive in vivo situation. Typically, we employ in vitro systems to further evaluate and refine findings generated from in vivo models.

A number of species including mice, rats, and pigs have been used as potential models of scarring in preclinical studies (Table 1). These studies include the use of excisional and incisional wounds in rodents and pigs, typically with macroscopic and/or microscopic endpoints for scarring, as well as the use of transgenic mice and more recently the Red Duroc pig, which exhibits some of the features of hypertrophic scarring seen in humans [54-56]. Most studies have not systematically compared the molecular, cellular, and tissue responses in these models to those in man. More importantly, most studies have not investigated the translation of therapeutic modulation in preclinical models to that in man. Addressing these issues is key to not only discovering and developing potential therapeutics for humans, but also investigating and understanding their 


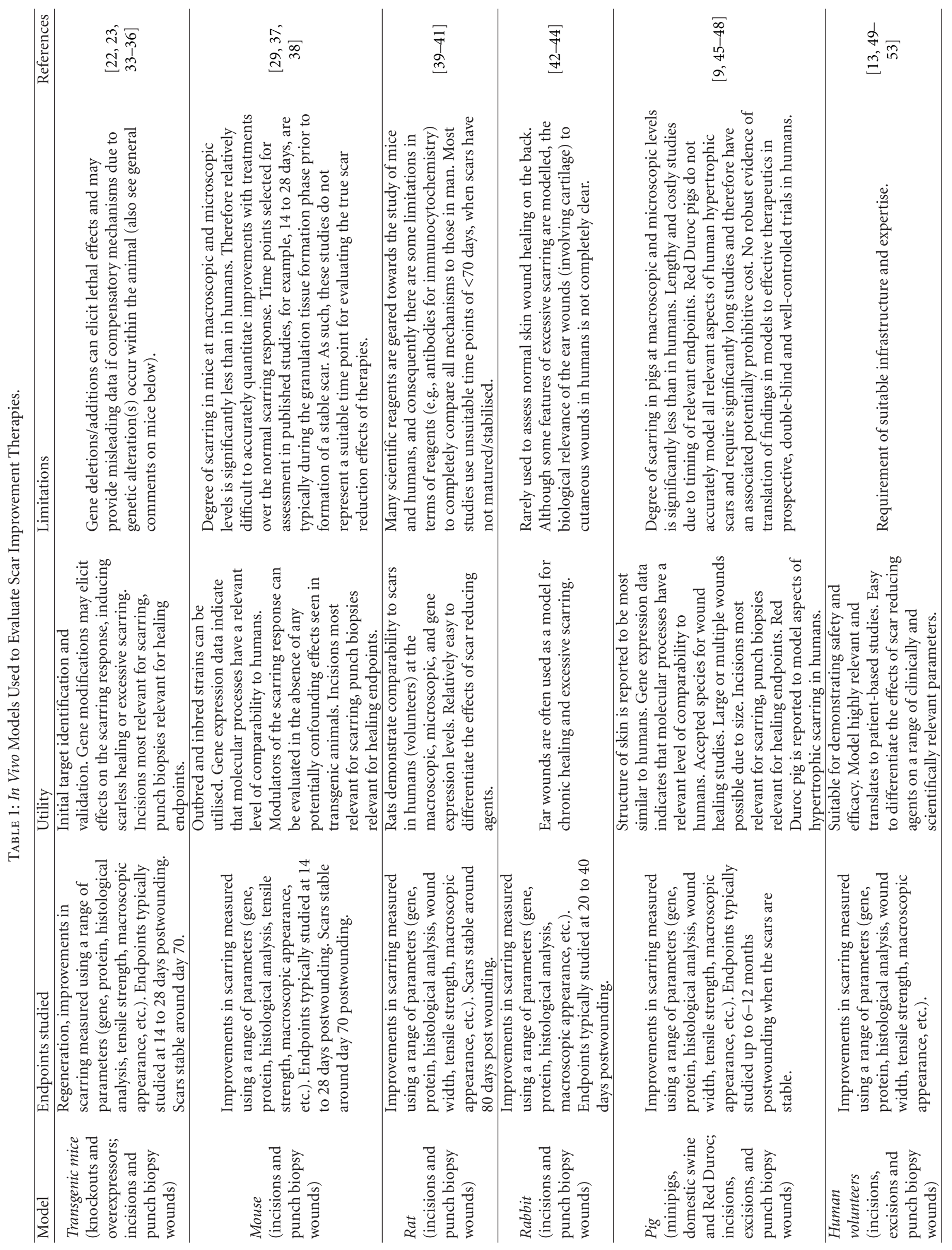




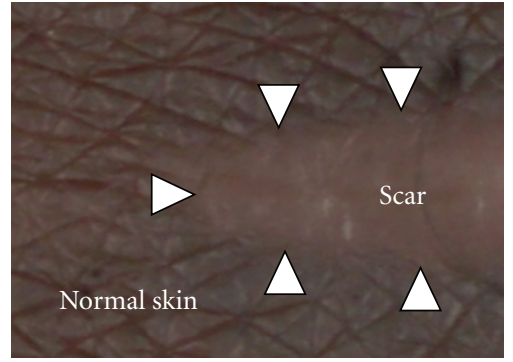

(a)

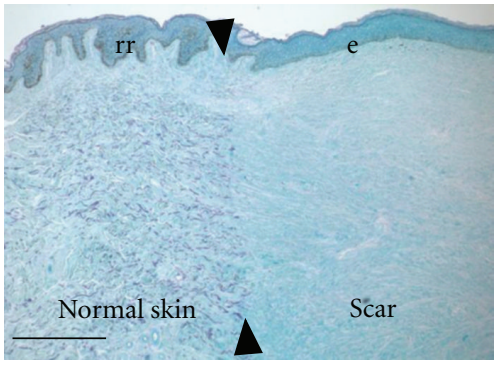

(b)

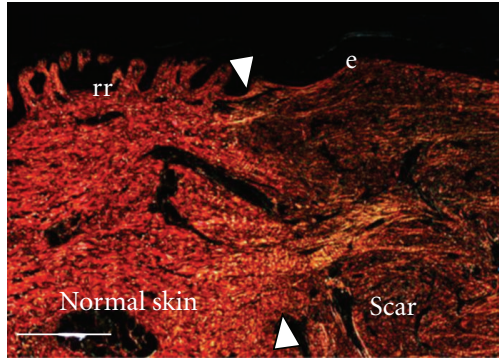

(c)

FIGURE 1: Scarring results from an abnormal deposition and organisation of collagen cutaneous scar in a noncaucasian subject at 12 months following a $1 \mathrm{~cm}$ full thickness incision to the inner aspect of the upper arm (a). Histological staining of the excised scar with Van Gieson's stain demonstrating collagen (blue/green) and elastin (purple) staining in the normal skin compared to scar tissue and a normal undulating epidermis with rete ridges in the normal skin compared to a flattened epidermis overlying the scar (b). Picrosirius red staining of the same scar viewed using polarised light (c), illustrating the normal "basket-weave" organisation of collagen in the normal skin resulting in organised light scattering (birefringence) compared to the abnormal organisation of collagen fibres within the scar resulting in a lack of birefringence. Arrowheads indicate the border of normal skin and scar tissue. Scale bars in (b) and (c) are $500 \mathrm{~mm}$. In (b) and (c), rr = rete ridges; e = epithelium.

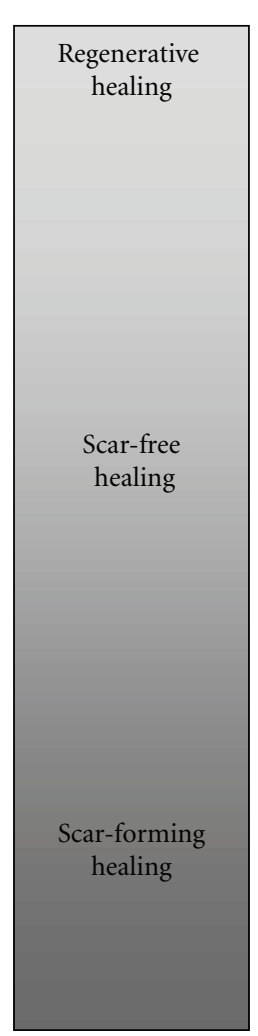

$\begin{array}{cc}\text { Species } & \text { Exemplar model/body site } \\ \text { Axolotl } & \text { Limbs } \\ \text { Mouse } & \\ \text { (MRL and } & \text { Ear } \\ \text { ther strains) } & \end{array}$

\begin{tabular}{|c|c|}
\hline $\begin{array}{l}\text { Mouse, rat, } \\
\text { pig, sheep, } \\
\text { marsupial, and }\end{array}$ & Embryo \\
\hline Human & $\begin{array}{l}\text { Liver, gums, oral mucosa, and } \\
\text { small cutaneous wounds } \\
\text { (all adult) }\end{array}$ \\
\hline
\end{tabular}

$\begin{array}{cc}\begin{array}{c}\text { Mouse, rat } \\ \text { pig, and human }\end{array} & \begin{array}{c}\text { Prophylactic cutaneous scar } \\ \text { reduction therapeutics (in adult } \\ \text { e.g., TGF } \beta 3\end{array} \\ \text { Axolotl } & \text { Incision (on flank) } \\ \text { Mouse } & \begin{array}{c}\text { Embryo (TGF } \beta 3 \text { knockout) } \\ \text { Incision (on dorsum) }\end{array} \\ \text { Mouse (MRL strain) } & \text { Cutaneous wounds } \\ \text { Human (children and } & \text { Hypertrophic scars } \\ \text { adults) } & \text { Keloids }\end{array}$

FIGURE 2: Scar-free to Scar-forming healing in vertebrates represents a continuous spectrum of responses.

mechanisms of action. We have addressed these issues in a series of extensive longitudinal studies utilising a range of endpoints and technologies both in pre-clinical models and humans. Our studies in mice, rats, and pigs have demonstrated that scars are stable and mature at $\geq 70$ days postwounding in mice/rats and $\geq 6$ months in pigs compared to 6 to 12 months in man. Comparison of the macroscopic appearance of these scars and the ability to assess a scar reduction effect within these pre-clinical models demonstrates that next to man, rats scar the worst and represent the most appropriate model (Figure 3 ). We have also compared the gene expression profiles during the 


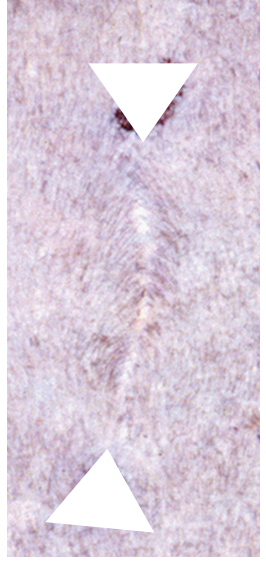

(a)

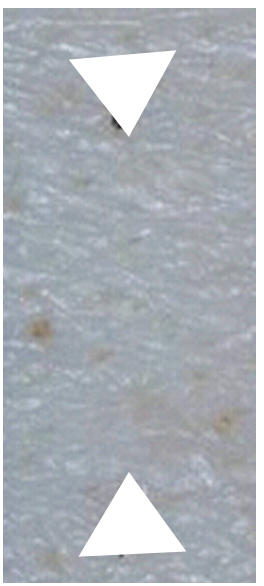

(e)

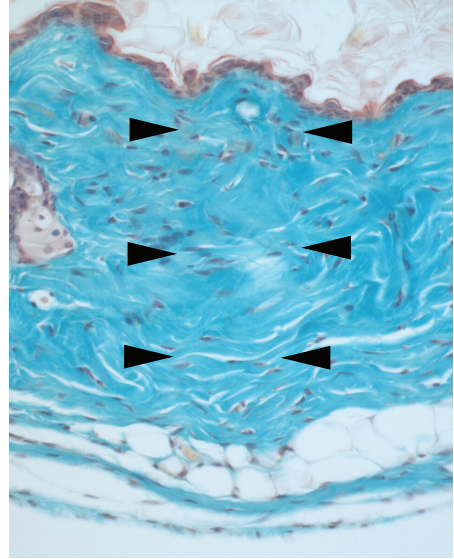

(b)

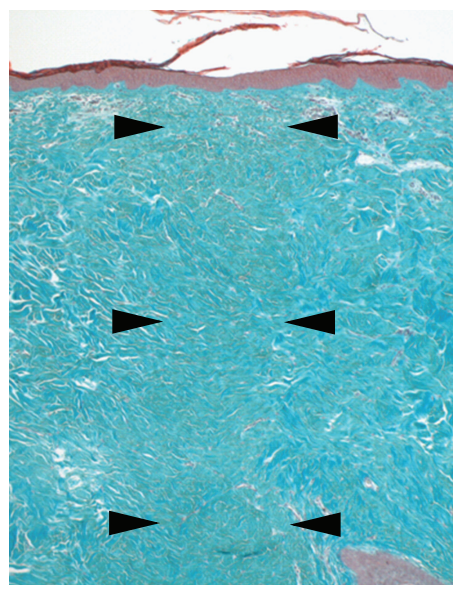

(f)

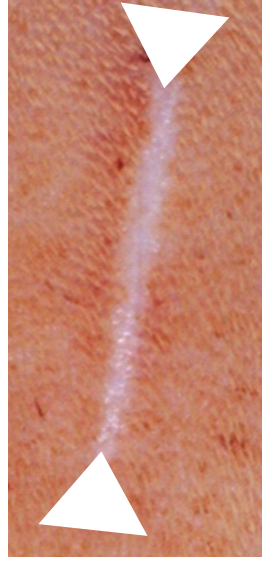

(c)

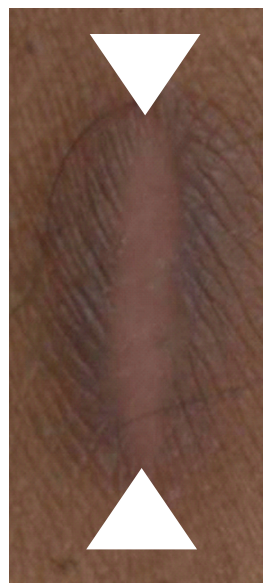

(g)

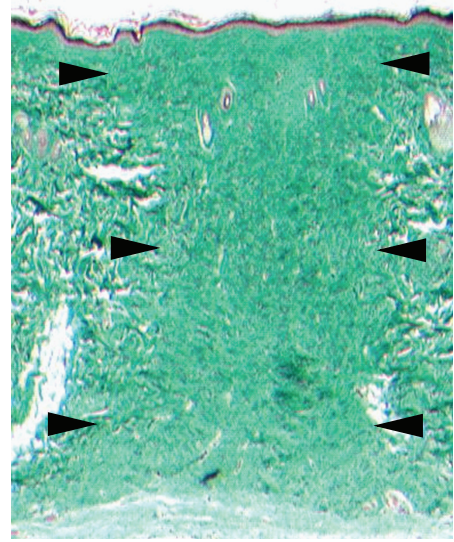

(d)

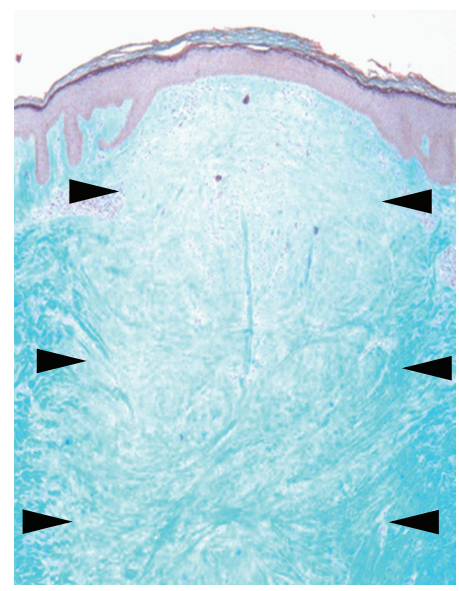

(h)

FIGURE 3: Comparison of Scarring at the Macroscopic and Microscopic Levels between experimental incisional wound models in pre-clinical species and humans. Scarring response in mice 70 days following a $1 \mathrm{~cm}$ full thickness incisional wound on the dorsum at the macroscopic ((a) arrowheads indicate ends of original wound) and microscopic ((b) arrowheads indicate scar) levels. Scarring response in rats 84 days following a $1 \mathrm{~cm}$ full thickness incisional wound on the dorsum at the macroscopic ((c) arrowheads indicate ends of original wound) and microscopic ( (d) arrowheads indicate scar) levels. Scarring response in pigs 168 days following a $1 \mathrm{~cm}$ full thickness incisional wound on the dorsum at the macroscopic ((e) arrowheads indicate ends of original wound) and microscopic ((f) arrowheads indicate scar) levels. Scarring response in humans 365 days following a $1 \mathrm{~cm}$ full thickness incisional wound on the inner aspect of the upper arm at the macroscopic $((\mathrm{g})$ arrowheads indicate ends of original wound) and microscopic ((h) arrowheads indicate scar) levels.

healing and scarring process in these pre-clinical species (up to 30,000 genes per sample per time point; $>300$ samples; 11 time points) and compared these to profiles in man (Caucasians and Noncaucasians; 30,000 genes per sample per time point; >250 samples; 9 time points). Analyses of the expression of genes involved in all the major phases of healing and scarring have clearly demonstrated molecular comparability, particularly between rat and man, indicating that the major difference between the healing and scarring in these models is time, with humans exhibiting an extended scar maturation phase [50, 51] (Figure 4). In addition, a number of genes/gene pathways have been identified from these studies in rats and man as further potential novel targets for the reduction of scarring in the skin.

\section{Translation from Pre-Clinical Studies to Clinical Efficacy}

As noted above, we have demonstrated that there is significant molecular and cellular comparability between the healing and scarring process in relevant pre-clinical models and in man. Unlike other therapeutic/chronic disease indications, it is important to note that healing and scarring represent an acute biological response that is conserved across species, and the progression of which is somewhat predictable. However, whilst a number of studies have reported therapeutic scar reduction in a variety of pre-clinical models, very few, if any, have demonstrated a translation of these findings to man in suitably designed, controlled, prospective, and randomised clinical trials [9-11]. 


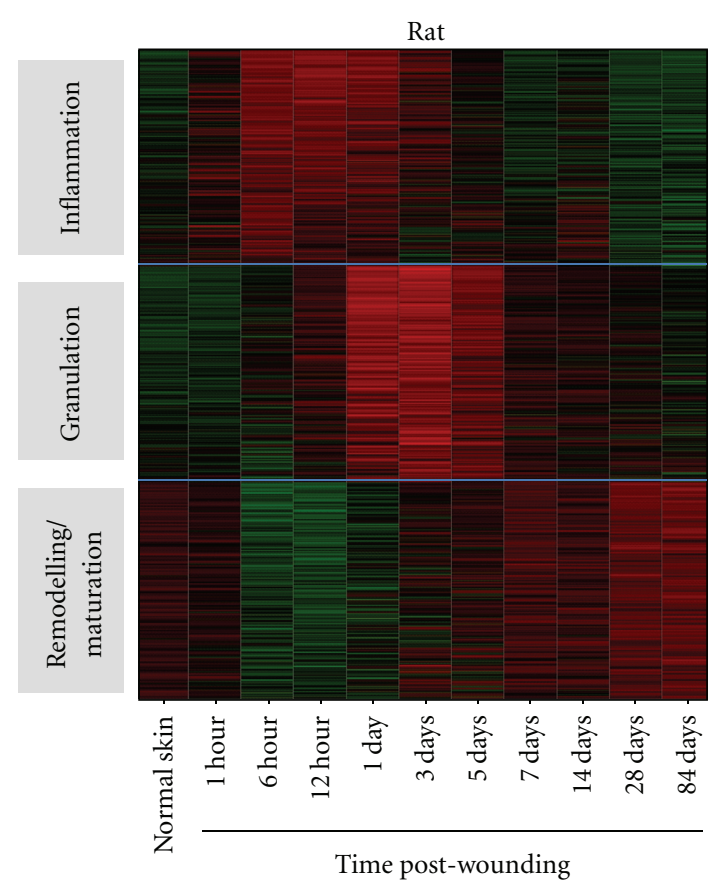

Low expression

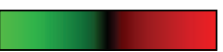

High expression

(a)

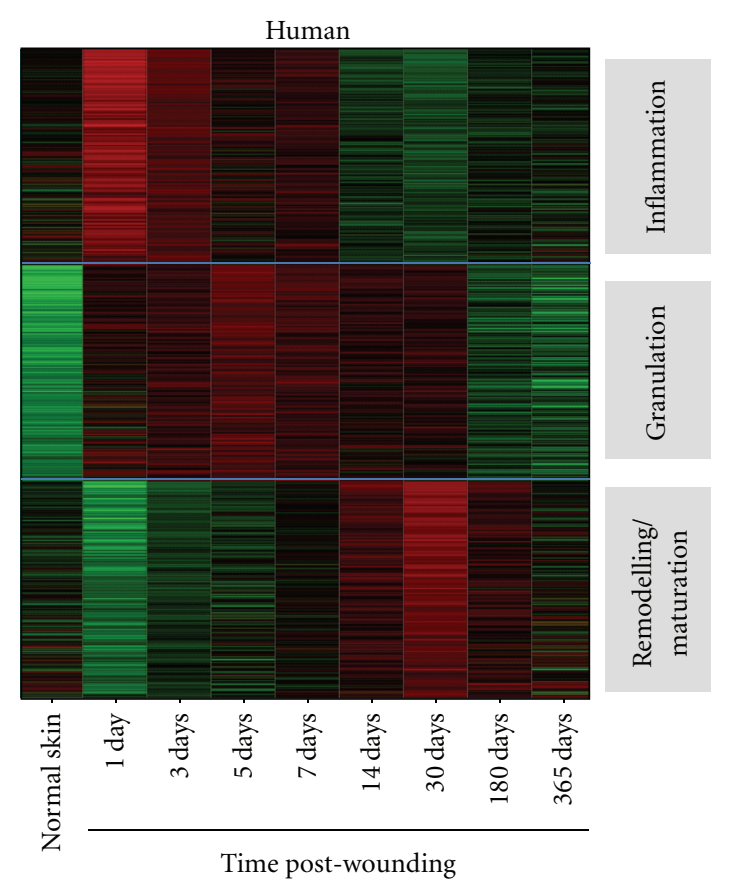

High expression

(b)

FIGURE 4: Gene expression in models of incisional wounds and scars in rat and man demonstrate molecular comparability heatmaps of samples of normal skin, wounds, and scars following $1 \mathrm{~cm}$ incisional wounds analysed for gene expression using Affymetrix Microarrays comparing the levels and timings of expression of genes involved in the inflammatory, granulation, remodelling, and maturation phases of healing and scarring (examples shown consist of comparison of $\sim 300$ genes for each phase).

Our approach for the development of therapies has focused on agents for the prophylactic reduction of scarring in man. This involves local administration of these agents to the margins of a wound at the time of surgery that leads to long-term improvements in scarring. The use of prophylactic, regenerative medicines is a novel pharmaceutical approach to scar improvement, and there are a number of challenges associated with this including: designing clinical trials in what is considered a pioneering therapeutic area, developing and validating suitable endpoints for evaluating the effectiveness of a prophylactic drug, where there is no established baseline against which improvements in scarring could be determined (since baseline would otherwise be normal skin before surgery or injury), and patients vary markedly in their propensity for scarring $[57,58]$. Our novel approach has been to utilise a withinsubject, placebo-controlled, human volunteer model, prior to starting patient studies, not only to establish local drug safety and tolerability but also to investigate a number of other key parameters including: optimal dose(s) and dosing frequency of the drug, evaluation of a variety of relevant endpoints, effects of the drug in subjects with different demographics, for example, sex, race, and age, effects of the drug in different wound types, for example, incisions and excisions. Studies to date have demonstrated that these prospective, double-blind, within-subject designs allow for a relevant and well-controlled approach for determining the proof-of-concept for potential therapies. Since there are no registered pharmaceuticals for the prophylactic reduction of scarring, we have had to pioneer this area in terms of clinical trial design and so have explored a variety of potential surgical models in patient populations to define their appropriateness for demonstration of drug effects.

We have successfully demonstrated a translation of scar reduction approaches from pre-clinical models to clinical studies, showing clear and robust effects with both ilodecakin (recombinant human interleukin-10, IL-10, Prevascar) in a Phase II clinical trial and with avotermin (recombinant human transforming growth factor beta 3 , TGF $\beta_{3}$, Juvista) in extensive Phase II volunteer- and patient-based studies $[49,52,59]$. For example, in three double-blind, placebocontrolled studies, intradermal avotermin (concentrations ranging from 0.25 to $500 \mathrm{ng} / 100 \mu \mathrm{L}$ per linear $\mathrm{cm}$ wound margin) was administered to both margins of $1 \mathrm{~cm}$, fullthickness skin incisions, before wounding and $24 \mathrm{~h}$ later, in healthy men and women [59]. Treatments (avotermin and placebo or standard wound care) were randomly assigned to wound sites by a computer-generated randomisation scheme, and within-participant controls compared avotermin versus placebo or standard wound care alone. Primary endpoints consisted of visual assessment of scar formation at 6 months and 12 months after wounding in two studies, and from week 6 to month 7 after wounding 

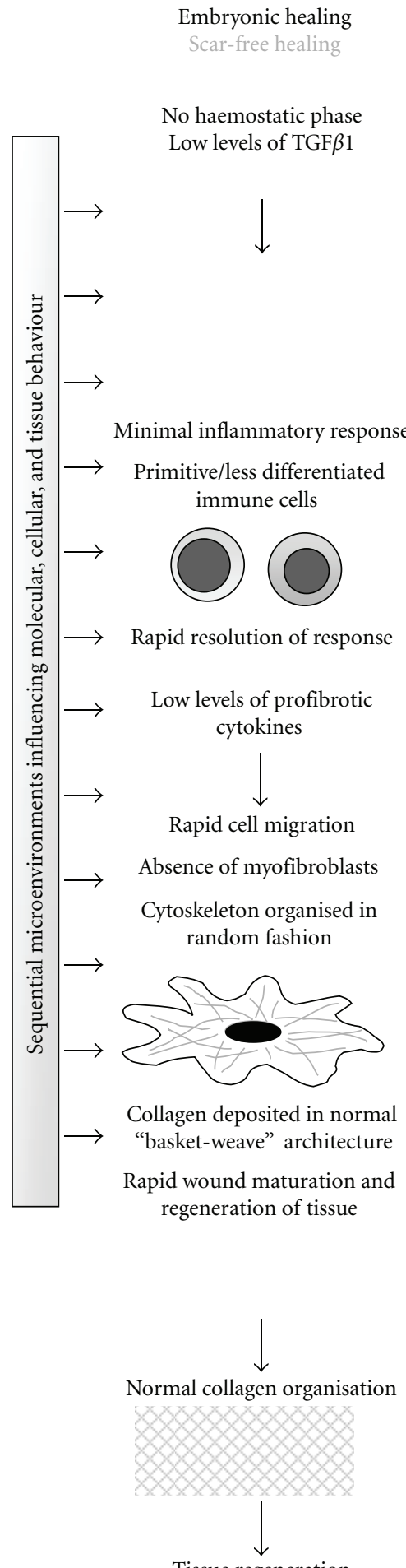

Tissue regeneration

$$
\begin{aligned}
& \text { Adult healing } \\
& \text { with scar } \\
& \text { reduction therapy }
\end{aligned}
$$

Platelet degranulation

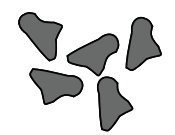

Application of therapy around the time of wounding alters initial and subsequent

microenvironments

"rerouting" the scarring response
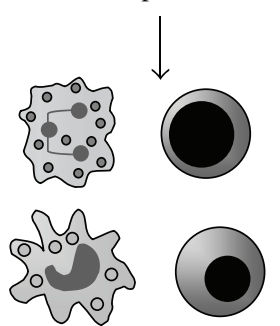

Alteration of inflammatory cell numbers/types/kinetics, and cytokines released

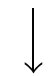

Alteration of numbers/levels /kinetics of myofibroblasts

Reduced collagen deposition

Cytoskeleton organised in more random fashion

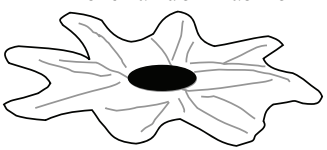

Collagen deposited in organisation more similar to normal skin

Increased protease activity and decreased protease inhibitors

Reduction in length of wound and scar maturation

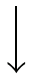

More normal collagen organisation

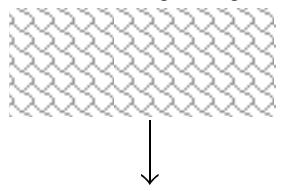

Scar improvement
Adult healing

without scar

reduction therapy

Platelet degranulation

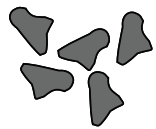

Release of profibrotic and proinflammatory mediators e.g., TGF $\beta 1$, PDGF

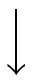

Neutrophils, monocytes, macrophages, and lymphocytes
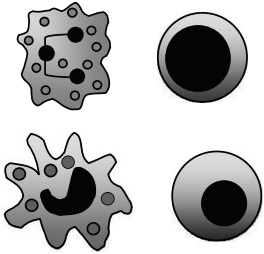

Release of profibrotic cytokines

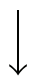

Myofibroblast differentiation

Production of excessive collagen

Formation of cytoskeleton (actin) stress fibres

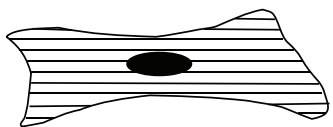

Collagen deposited in abnormal parallel organisation

Persistence of myofbroblasts decreased protease activity and increased protease inhibitors

Extended wound and scar maturation including angiogenesis

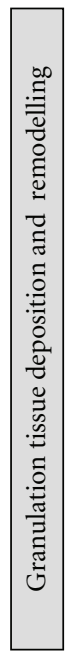

Abnormal collagen organisation

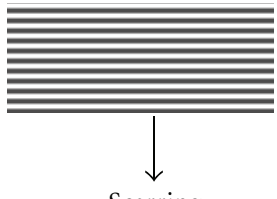

Scarring

FIGURE 5: Mechanisms and processes associated with scar-free healing, scar-forming healing and prophylactic scar reduction therapies.

in the third study [59]. All investigators, participants, and scar assessors were blinded to treatment and efficacy analyses.

In two studies, avotermin $50 \mathrm{ng} / 100 \mu \mathrm{L}$ per linear $\mathrm{cm}$ significantly improved median score on a $100-\mathrm{mm}$ visual analogue scale (VAS) by $5 \mathrm{~mm}$ (range -2 to $14 ; P=$
$.001)$ at month 6 and $8 \mathrm{~mm}(-29$ to $18 ; P=.0230)$ at month 12. In the third study, avotermin significantly improved total scar scores at all concentrations versus placebo (mean improvement: from $14.84 \mathrm{~mm}$ [95\% CI 5.524.2 at $5 \mathrm{ng} / 100 \mu \mathrm{L}$ per linear $\mathrm{cm}$ to $64.25 \mathrm{~mm}$ [49.4-79.1] at $500 \mathrm{ng} / 100 \mu \mathrm{L}$ per linear $\mathrm{cm})$. Nine [60\%] scars treated 
with avotermin at $50 \mathrm{ng} / 100 \mu \mathrm{L}$ per linear $\mathrm{cm}$ showed $25 \%$ or less abnormal orientation of collagen fibres in the reticular dermis versus five [33\%] placebo scars. After only 6 weeks from wounding, avotermin at $500 \mathrm{ng} / 100 \mu \mathrm{L}$ per linear $\mathrm{cm}$ improved VAS score by $16.12 \mathrm{~mm}$ (95\% CI 10.61-21.63).

Similarly, in another Phase II clinical study, intradermal administration of ilodecakin was well tolerated, and at concentrations of $5 \mathrm{ng} / 100 \mu \mathrm{L}$ and $25 \mathrm{ng} / 100 \mu \mathrm{L}$ per linear $\mathrm{cm}$ wound margin, resulted in statistically significant improvements $(P<.05)$ in scar appearance with multiple endpoints compared with controls at 12 months postwounding.

Taken together, the results of these clinical studies have demonstrated that acute, local applications of both avotermin and ilodecakin have the potential to provide an accelerated and permanent improvement in scarring in humans.

\section{Understanding the Mechanisms of Action of Prophylactic Scar Improvement Therapies}

Following cutaneous injury, numerous interacting and dynamic molecular and cellular events are initiated. These include a series of cascades involved in amplification, induction, repression, feed-forward, and feed-back processes that result in a series of sequential and temporal microenvironments within the wound, with which resident cells and those infiltrating the wound interact (Figure 5). The molecular and cellular behaviour of the wound is dependent on the composition of the tissue microenvironment at any one time. Therefore, any alteration of the molecular or functional behaviour of cells (e.g., by appropriate therapeutic modulation) results in changes to subsequent wound microenvironments and ultimately affects the tissue response. In wound healing and scarring, like embryonic development, the system contains a number of pathways exhibiting multiple redundancy which gives robustness to the system. If minor pathways are therapeutically modulated, whilst subsequent microenvironments may be rerouted, they nevertheless result in a scarring phenotype. However, modulation of a major pathway that alters multiple microenvironments synergistically, results in significant alterations and a major "rerouting" of the healing response, leading to the propagation and amplification of a phenotype of improved scar appearance (Figure 5). From our studies in a range of pre-clinical species, we have identified a number of key pathways that are central to generating a scarring response. Our use of human volunteers, in an experimental medicine context, has also rapidly allowed us to confirm which of these identified pathways are relevant in man and hence identify and progress new therapeutics into the clinical arena.

\section{Summary}

The reduction of scarring represents a clear medical need. Currently, there are no registered pharmaceuticals for the prophylactic improvement of scarring, and no single therapy is accepted universally as the standard of care. The spectrum of healing following wounding ranges from the ability to completely regenerate tissue through to the formation of hypertrophic and keloid scars. Importantly, a number of studies have demonstrated that all mammalian organisms retain the ability to heal via both regenerative and scarforming processes. This is the key in terms of being able to therapeutically modulate the healing response in adults and reduce the severity of subsequent scarring.

Our approach to the development of therapies has focused on agents for the prophylactic reduction of scarring. This has been significantly aided by our extensive studies, comparing and understanding the molecular processes and scarring phenotypes in pre-clinical models, as well as our pioneering use of human volunteers both in longitudinal scarring studies and in an experimental medicine context which has rapidly allowed us to confirm which of the identified pathways are relevant in man. The translation of findings in the rat pre-clinical model to man has been shown in suitably designed and controlled prospective and randomised clinical trials.

In terms of the mechanisms of action, the prophylactic administration of scar improvement therapeutics results in significant alterations and a major "rerouting" of the healing response, resulting in the propagation and amplification of a phenotype of improved scar appearance, by virtue of a change in the architecture of the deposited collagen.

The understanding of the scientific basis of scar-free and scar-forming healing and our pioneering approach to the development of therapies have allowed the identification and progression of new treatments. We have demonstrated that the development of pharmaceuticals for prophylactic scar improvement, that are additive to good surgical technique, is achievable, resulting in new therapies with a sound scientific basis and clear evidence of effectiveness in robust clinical trials.

\section{References}

[1] D. A. McGrouther, "Facial disfigurement," British Medical Journal, vol. 314, no. 7086, p. 991, 1997.

[2] R. Robert, W. Meyer, S. Bishop, L. Rosenberg, L. Murphy, and P. Blakeney, "Disfiguring burn scars and adolescent selfesteem," Burns, vol. 25, no. 7, pp. 581-585, 1999.

[3] R. Newell, "Psychological difficulties amongst plastic surgery ex-patients following surgery to the face: a survey," British Journal of Plastic Surgery, vol. 53, no. 5, pp. 386-392, 2000.

[4] A. M. Layton, "Optimal management of acne to prevent scarring and psychological sequelae," American Journal of Clinical Dermatology, vol. 2, no. 3, pp. 135-141, 2001.

[5] N. Rumsey, A. Clarke, and P. White, "Exploring the psychosocial concerns of outpatients with disfiguring conditions," Journal of Wound Care, vol. 12, no. 7, pp. 247-252, 2003.

[6] J. W. Lawrence, J. A. Fauerbach, L. Heinberg, and M. Doctor, "Visible vs hidden scars and their relation to body esteem," Journal of Burn Care and Rehabilitation, vol. 25, no. 1, pp. 2532, 2004.

[7] S. M. Valente, "Visual disfigurement and depression," Plastic Surgical Nursing, vol. 24, no. 4, pp. 140-146, 2004.

[8] A. Bayat and D. A. McGrouther, "Clinical management of skin scarring," Skinmed, vol. 4, no. 3, pp. 165-173, 2005. 
[9] K. Meier and L. B. Nanney, "Emerging new drugs for scar reduction," Expert Opinion on Emerging Drugs, vol. 11, no. 1, pp. 39-47, 2006.

[10] R. G. Reish and E. Eriksson, "Scars: a review of emerging and currently available therapies," Plastic and Reconstructive Surgery, vol. 122, no. 4, pp. 1068-1078, 2008.

[11] R. G. Reish and E. Eriksson, "Scar treatments: preclinical and clinical studies," Journal of the American College of Surgeons, vol. 206, no. 4, pp. 719-730, 2008.

[12] R. L. McCallion and M. W. J. Ferguson, "Fetal wound healing and the development of antiscarring therapies for adult wound healing," in The Molecular and Cellular Biology of Wound Repair, R. A. F. Clark, Ed., pp. 561-600, Plenum Press, New York, NY, USA, 1996.

[13] M. W. J. Ferguson and S. O’Kane, "Scar-free healing: from embryonic mechanism to adult therapeutic intervention," Philosophical Transactions of the Royal Society B, vol. 359, no. 1445, pp. 839-850, 2004.

[14] J. R. Armstrong and M. W. J. Ferguson, "Ontogeny of the skin and the transition from scar-free to scarring phenotype during wound healing in the pouch young of a marsupial, Monodelphis domestica," Developmental Biology, vol. 169, no. 1, pp. 242-260, 1995.

[15] A. J. Cowin, M. P. Brosnan, T. M. Holmes, and M. W. J. Ferguson, "Endogenous inflammatory response to dermal wound healing in the fetal and adult mouse," Developmental Dynamics, vol. 212, no. 3, pp. 385-393, 1998.

[16] D. J. Whitby and M. W. J. Ferguson, "Immunohistochemical localization of growth factors in fetal wound healing," Developmental Biology, vol. 147, no. 1, pp. 207-215, 1991.

[17] S. O'Kane and M. W. J. Ferguson, "Transforming growth factor $\beta$ s and wound healing," International Journal of Biochemistry and Cell Biology, vol. 29, no. 1, pp. 63-78, 1997.

[18] M. Shah, P. Rorison, and M. W. J. Ferguson, "The role of transforming growth factors beta in cutaneous scarring," in Scarless Wound Healing, H. G. Garg and M. T. Longaker, Eds., pp. 213-226, Marcel Dekker, New York, NY, USA, 2000.

[19] A. J. Cowin, T. M. Holmes, P. Brosnan, and M. W. J. Ferguson, "Expression of TGF- $\beta$ and its receptors in murine fetal and adult dermal wounds," European Journal of Dermatology, vol. 11, no. 5, pp. 424-431, 2001.

[20] M. W. J. Ferguson, D. J. Whitby, M. Shah, J. Armstrong, J. W. Siebert, and M. T. Longaker, "Scar formation: the spectral nature of fetal and adult wound repair," Plastic and Reconstructive Surgery, vol. 97, no. 4, pp. 854-860, 1996.

[21] B. Gawronska-Kozak, "Regeneration in the ears of immunodeficient mice: identification and lineage analysis of mesenchymal stem cells," Tissue Engineering, vol. 10, no. 7-8, pp. 12511265, 2004.

[22] B. Gawronska-Kozak, M. Bogacki, J.-S. Rim, W. T. Monroe, and J. A. Manuel, "Scarless skin repair in immunodeficient mice," Wound Repair and Regeneration, vol. 14, no. 3, pp. 265276, 2006.

[23] A. H. M. Beare, A. D. Metcalfe, and M. W. J. Ferguson, "Location of injury influences the mechanisms of both regeneration and repair within the MRL/MpJ mouse," Journal of Anatomy, vol. 209, no. 4, pp. 547-559, 2006.

[24] A. S. Colwell, T. M. Krummel, M. T. Longaker, and H. P. Lorenz, "An in vivo mouse excisional wound model of scarless healing," Plastic and Reconstructive Surgery, vol. 117, no. 7, pp. 2292-2296, 2006.

[25] M. E. Schrementi, A. M. Ferreira, C. Zender, and L. A. DiPietro, "Site-specific production of TGF- $\beta$ in oral mucosal and cutaneous wounds," Wound Repair and Regeneration, vol. 16 , no. 1, pp. 80-86, 2008.

[26] A. D. Metcalfe, H. Willis, A. Beare, and M. W. J. Ferguson, "Characterizing regeneration in the mammalian external ear," Journal of Anatomy, vol. 209, no. 4, pp. 439-446, 2006.

[27] A. J. Singer and R. A. F. Clark, "Cutaneous wound healing," New England Journal of Medicine, vol. 341, no. 10, pp. 738746, 1999.

[28] S.-C. Su, E. A. Mendoza, H.-I. Kwak, and K. J. Bayless, "Molecular profile of endothelial invasion of three-dimensional collagen matrices: insights into angiogenic sprout induction in wound healing," American Journal of Physiology, vol. 295, no. 5, pp. C1215-C1229, 2008.

[29] R. Mori, T. J. Shaw, and P. Martin, "Molecular mechanisms linking wound inflammation and fibrosis: knockdown of osteopontin leads to rapid repair and reduced scarring," Journal of Experimental Medicine, vol. 205, no. 1, pp. 43-51, 2008.

[30] C. J. Kirkpatrick, S. Fuchs, M. Iris Hermanns, K. Peters, and R. E. Unger, "Cell culture models of higher complexity in tissue engineering and regenerative medicine," Biomaterials, vol. 28, no. 34, pp. 5193-5198, 2007.

[31] J. C. Dallon and H. P. Ehrlich, "A review of fibroblastpopulated collagen lattices," Wound Repair and Regeneration, vol. 16, no. 4, pp. 472-479, 2008.

[32] A. A. Ucuzian and H. P. Greisler, "In vitro models of angiogenesis," World Journal of Surgery, vol. 31, no. 4, pp. 654663, 2007.

[33] G. Proetzel, S. A. Pawlowski, M. V. Wiles et al., "Transforming growth factor- $\beta 3$ is required for secondary palate fusion," Nature Genetics, vol. 11, no. 4, pp. 409-414, 1995.

[34] M. Isoda, S. Ueda, S. Imayama, and K. Tsukahara, "New formulation of chemical peeling agent: histological evaluation in sun-damaged skin model in hairless mice," Journal of Dermatological Science, supplement 1, pp. S60-S67, 2001.

[35] K. C. Flanders, C. D. Major, A. Arabshahi et al., "Interference with transforming growth factor- $\beta / \mathrm{Smad} 3$ signaling results in accelerated healing of wounds in previously irradiated skin," American Journal of Pathology, vol. 163, no. 6, pp. 2247-2257, 2003.

[36] S. B. Cho, C. O. Park, W. G. Chung, K. H. Lee, J. B. Lee, and K. Y. Chung, "Histometric and histochemical analysis of the effect of trichloroacetic acid concentration in the chemical reconstruction of skin scars method," Dermatologic Surgery, vol. 32, no. 10, pp. 1231-1236, 2006.

[37] S. Aarabi, K. A. Bhatt, Y. Shi et al., "Mechanical load initiates hypertrophic scar formation through decreased cellular apoptosis," FASEB Journal, vol. 21, no. 12, pp. 3250-3261, 2007.

[38] C. Qiu, P. Coutinho, S. Frank et al., "Targeting connexin43 expression accelerates the rate of wound repair," Current Biology, vol. 13, no. 19, pp. 1697-1703, 2003.

[39] C. M. Dang, S. R. Beanes, H. Lee, X. Zhang, C. Soo, and K. Ting, "Scarless fetal wounds are associated with an increased matrix metalloproteinase-to-tissue-derived inhibitor of metalloproteinase ratio," Plastic and Reconstructive Surgery, vol. 111, no. 7, pp. 2273-2285, 2003.

[40] M. Birch, A. Tomlinson, and M. W. Ferguson, "Animal models for adult dermal wound healing," Methods in Molecular Medicine, vol. 117, pp. 223-235, 2005.

[41] A. S. Colwell, S. R. Beanes, C. Soo et al., "Increased angiogenesis and expression of vascular endothelial growth factor during scarless repair," Plastic and Reconstructive Surgery, vol. 115, no. 1, pp. 204-212, 2005. 
[42] O. Kloeters, A. Tandara, and T. A. Mustoe, "Hypertrophic scar model in the rabbit ear: a reproducible model for studying scar tissue behavior with new observations on silicone gel sheeting for scar reduction," Wound Repair and Regeneration, vol. 15, supplement 1, pp. S40-S45, 2007.

[43] Z. B. Kryger, M. Sisco, N. K. Roy, L. Lu, D. Rosenberg, and T. A. Mustoe, "Temporal expression of the transforming growth factor-beta pathway in the rabbit ear model of wound healing and scarring," Journal of the American College of Surgeons, vol. 205, no. 1, pp. 78-88, 2007.

[44] I. Kim, J. E. Mogford, C. Witschi, M. Nafissi, and T. A. Mustoe, "Inhibition of prolyl 4-hydroxylase reduces scar hypertrophy in a rabbit model of cutaneous scarring," Wound Repair and Regeneration, vol. 11, no. 5, pp. 368-372, 2003.

[45] L. S. Moy, S. Peace, and R. L. Moy, "Comparison of the effect of various chemical peeling agents in a mini-pig model," Dermatologic Surgery, vol. 22, no. 5, pp. 429-432, 1996.

[46] M. M. W. Ulrich, M. Verkerk, L. Reijnen, M. Vlig, A. J. Van Den Bogaerdt, and E. Middelkoop, "Expression profile of proteins involved in scar formation in the healing process of full-thickness excisional wounds in the porcine model," Wound Repair and Regeneration, vol. 15, no. 4, pp. 482-490, 2007.

[47] C. L. Gallant, M. E. Olson, and D. A. Hart, "Molecular, histologic, and gross phenotype of skin wound healing in red Duroc pigs reveals an abnormal healing phenotype of hypercontracted, hyperpigmented scarring," Wound Repair and Regeneration, vol. 12, no. 3, pp. 305-319, 2004.

[48] K. Q. Zhu, G. J. Carrougher, O. P. Couture, C. K. Tuggle, N. S. Gibran, and L. H. Engrav, "Expression of collagen genes in the cones of skin in the Duroc/Yorkshire porcine model of fibroproliferative scarring," Journal of Burn Care and Research, vol. 29, no. 5, pp. 815-827, 2008.

[49] N. L. Occleston, S. O'Kane, N. Goldspink, and M. W. J. Ferguson, "New therapeutics for the prevention and reduction of scarring," Drug Discovery Today, vol. 13, no. 21-22, pp. 973 981, 2008.

[50] J. S. Bond, J. A. L. Duncan, A. Sattar et al., "The maturation of the human scar: an observational study," Plastic and Reconstructive Surgery, vol. 121, no. 5, pp. 1650-1658, 2008.

[51] J. S. Bond, J. A.L. Duncan, T. Mason et al., "Scar redness in humans: how long does it persist after incisional and excisional wounding?" Plastic and Reconstructive Surgery, vol. 121, no. 2, pp. 487-496, 2008.

[52] N. L. Occleston, H. G. Laverty, S. O'Kane, and M. W. J. Ferguson, "Prevention and reduction of scarring in the skin by transforming growth factor beta 3 (TGF 33 ): from laboratory discovery to clinical pharmaceutical," Journal of Biomaterials Science, Polymer Edition, vol. 19, no. 8, pp. 1047-1063, 2008.

[53] J. S. Bond, J. A. L. Duncan, T. Mason et al., "Scar redness in humans: how long does it persist after incisional and excisional wounding?" Plastic and Reconstructive Surgery, vol. 121, no. 2, pp. 487-496, 2008.

[54] N. Harunari, K. Q. Zhu, R. T. Armendariz et al., "Histology of the thick scar on the female, red Duroc pig: final similarities to human hypertrophic scar," Burns, vol. 32, no. 6, pp. 669-677, 2006.

[55] K. Q. Zhu, G. J. Carrougher, N. S. Gibran, F. F. Isik, and L. H. Engrav, "Review of the female Duroc/Yorkshire pig model of human fibroproliferative scarring," Wound Repair and Regeneration, vol. 15, supplement 1, pp. S32-S39, 2007.

[56] Y. Xie, K. Q. Zhu, H. Deubner et al., "The microvasculature in cutaneous wound healing in the female red duroc pig is similar to that in human hypertrophic scars and different from that in the female yorkshire pig," Journal of Burn Care and Research, vol. 28, no. 3, pp. 500-506, 2007.

[57] T. A. Mustoe, R. D. Cooter, M. H. Gold et al., "International clinical recommendations on scar management," Plastic and Reconstructive Surgery, vol. 110, no. 2, pp. 560-571, 2002.

[58] A. Bayat, D. A. McGrouther, and M. W. J. Ferguson, "Skin scarring," British Medical Journal, vol. 326, no. 7380, pp. 8892, 2003.

[59] M. W. Ferguson, J. Duncan, J. Bond et al., "Prophylactic administration of avotermin for improvement of skin scarring: three double-blind, placebo-controlled, phase I/II studies," The Lancet, vol. 373, no. 9671, pp. 1264-1274, 2009. 


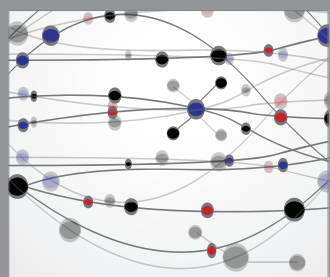

The Scientific World Journal
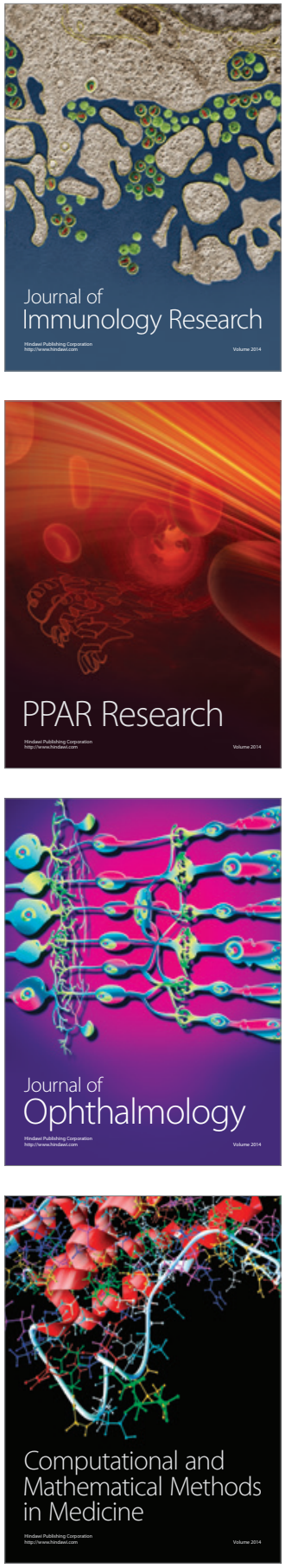

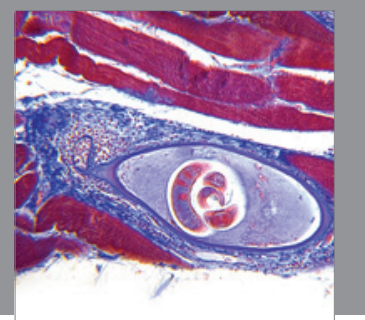

Gastroenterology

Research and Practice
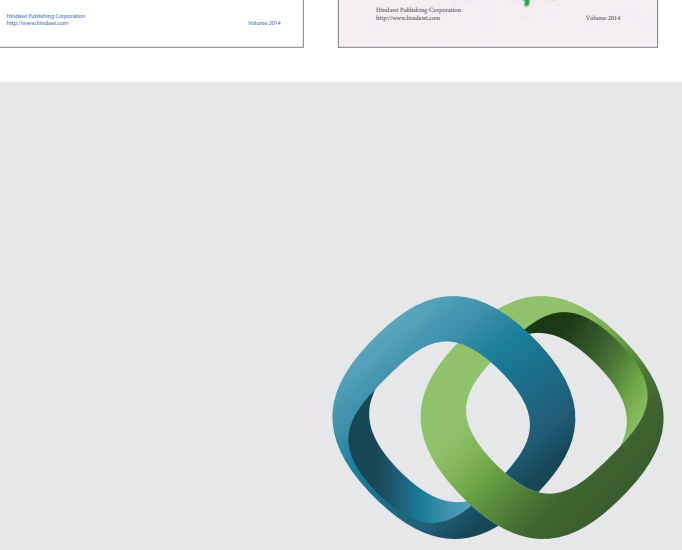

\section{Hindawi}

Submit your manuscripts at

http://www.hindawi.com
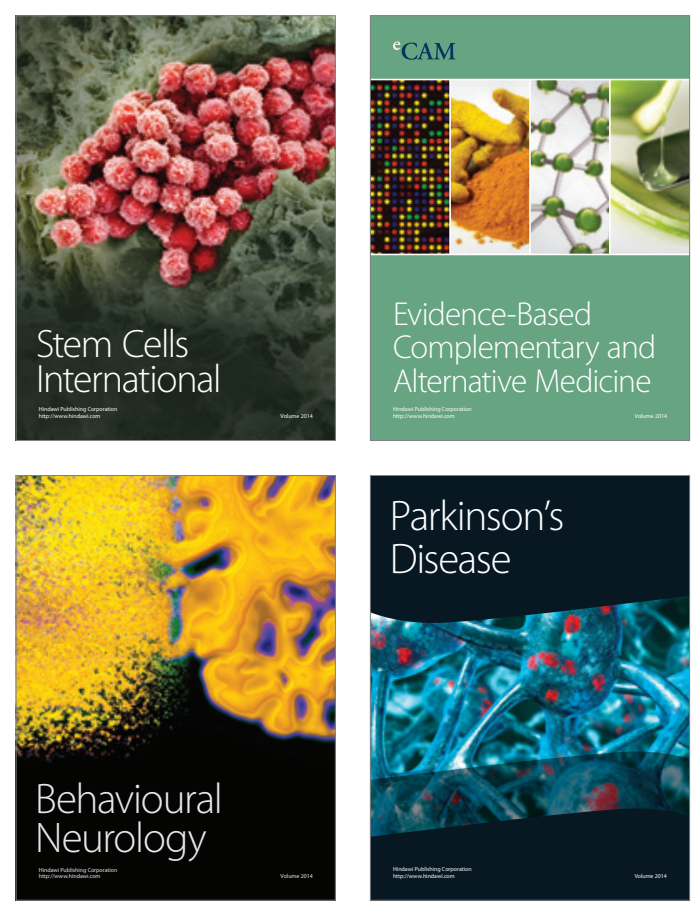

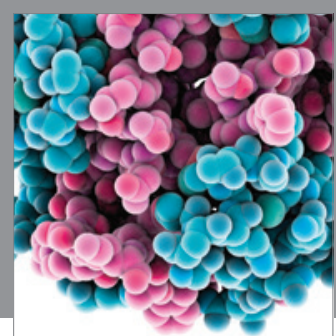

Journal of
Diabetes Research

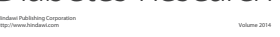

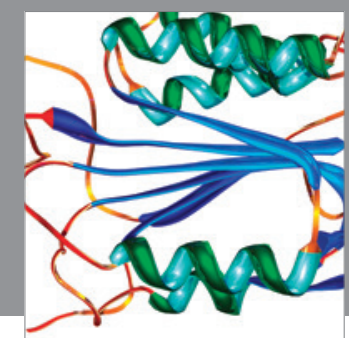

Disease Markers
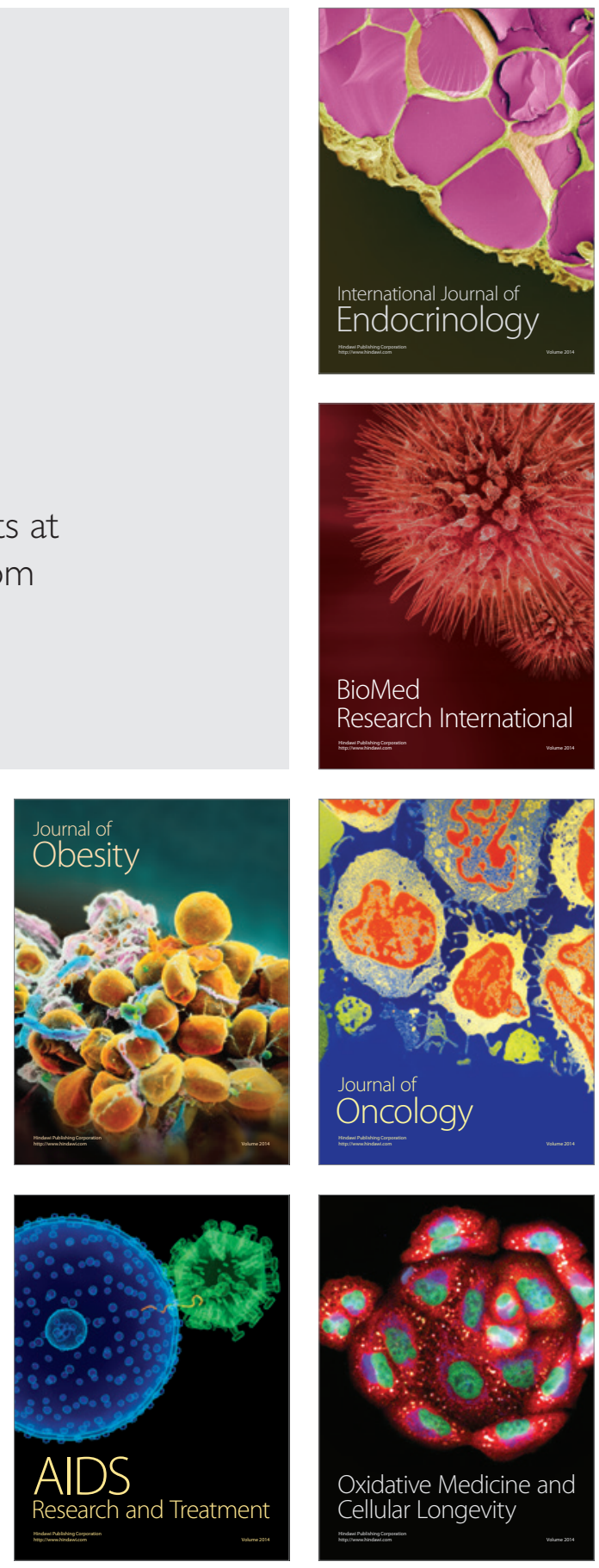